\title{
DESEQUILIBRIOS HIDROGRÁFICOS EN ESPAÑA Y TRASVASES A LA VERTIENTE MEDITERRÁNEA: UTOPÍAS Y REALIZACIONES*
}

\author{
Antonio Gil Olcina
}

\begin{abstract}
RESUMEN
Este artículo analiza la diacronía de los trasvases en la Península Ibérica, desde los proyectos iniciales en el bajo medievo a la problemática que enfrenta la nueva Ley de Aguas. Se concede especial atención a las actuaciones del reformismo ilustrado, legislación decimonónica de aguas, propuesta de corrección del desequilibrio hidrográfico contenida en el I Plan Nacional de Obras Hidráulicas, travase Tajo-Segura e intereses contrapuestos en las transferencias de recursos hídricos actualmente planteadas.
\end{abstract}

\begin{abstract}
SUMMARY
This article analyses the complexity of the water transfers in the Iberian Peninsula, from the initial projects in the early Middle Age, to the present problems encountered by the new Ley de Aguas (Water Law). The achievements of the «reformismo ilustrado», as well as the 19th. century water laws, the proposal for correcting the hydrographical differences contained in the Ist. Hydraulic Works National Plan, the transfer Tajo-Segura and the antagonistic interests raised by the transferring of hydric resources presently proposed, are especially dealt with.
\end{abstract}

Los rasgos físicos de la Península Ibérica motivan una acusada desigualdad de recursos hídricos entre sus vertientes atlántica y mediterránea. Esta situación obedece a condiciones climáticas e hidrográficas, ya que, con la notoria excepción del Ebro, los mayores colectores afluyen al primero de dichos ámbitos. Nada tiene de extraño, sino todo lo contrario, que las primeras peticiones de trasvases documentadas correspondan a la región climática del

* Esta ponencia, expuesta en el seminario organizado por la Universidad Internacional Menéndez Pelayo acerca de «Los conflictos territoriales por el agua en los estados normediterráneos», es objeto de publicación en el marco del proyecto de investigación sobre «Insuficiencia de recursos hídricos y riesgo de avenidas fluviales en las regiones de Valencia y Murcia», patrocinado por la Comisión Interministerial de Ciencia y Tecnología. 
Sureste, cuyo régimen de precipitaciones, desvaído reflejo del mediterráneo, viene caracterizado por la acentuada escasez y elevada irregularidad interanual de las mismas, con durísimas y prolongadas sequías. Se hallaba aún el mencionado espacio dividido entre las coronas de Castilla y Aragón y el reino nazarí, cuando, en 1370, la importante plaza fronteriza de Lorca, llave del reino de Murcia y cabecera de un dilatado término, planteó a Enrique II la necesidad de transferir a su regadío, ampliamente deficitario, agua de las fuentes de Archivel o Caravaca, que brotan en las estribaciones meridionales de la sierra de Taibilla ${ }^{1}$. Medio siglo después, el 27 de mayo de 1420, la villa de Elche, que tan sólo disponía para atender su extensa huerta del débito exiguo y excesivamente salino del Vinalopó, decidió, según parece, por primera vez, gestionar el trasvase de una porción del Júcar. A tenor del acuerdo, el concejo ilicitano consiguió que Villena y Chinchilla, territorios de la corona de Castilla por donde había de discurrir la conducción, concediesen su beneplácito².

El aprovechamiento de las fuentes de Archivel por el regadío lorquino o del gasto derivado del Júcar en el Bajo Vinalopó han sido, con diferentes versiones en cada caso y momento, proyectos recurrentes durante siglos, reavivados una y otra vez por intensas sequías, sin que ninguno haya alcanzado a materializarse; todavía hoy, seis siglos después, el Medio Vinalopó, en situación crítica, abriga esperanzas de enjugar su angustioso déficit hídrico con sobrantes del Júcar. Fácilmente se entiende que, en épocas tan tempranas, las posibilidades de ejecución de ambos designios, con sus respectivos cúmulos de dificultades técnicas, políticas y económicas, insuperables en la práctica, más que remotas, eran nulas.

\section{Reconocimientos, nivelaciones y esbozos de trasvases en los siglos XVI y XVII}

Ambas centurias integran una etapa destacada de la historia hidráulica española; ello se debe, primordialmente, a la construcción de embalses para riego. Durante el siglo XVI se levantan los de Almansa y Tibi; éste, reservorio modélico mucho tiempo, adquirió, como prototipo a imitar, gran celebridad ${ }^{3}$. En el XVII se realizan los de Elche, Elda, Onteniente y, probablemente, los de Petrel y Alcora, mientras corresponde al XVIII la interesante presa-bóveda de Relleu ${ }^{4}$. Como señala López Gómez ${ }^{5}$, la cifra te pantanos en las regiones valenciana y murciana, que incluye asimismo un intento fallido en el Guadalentín, resulta extraordinaria para la época; a ellos hay que sumar el llamado Mar de Ontígola en Aranjuez, con planos de Juan de Herrera, y el de la Foz de Arguís, cuyas obras dieron comienzo en 1686.

Con la oscura sombra que proyecta la pérdida de la hegemonía en Europa, el XVII español ha sido, con frecuencia, víctima de una interpretación muy negativa, no siempre cierta, y enteramente injustificada en cuanto a realizaciones y proyectos hidráulicos, que no se reducen a los pantanos, por más que éstos, entre los que no falta alguna pieza maestra con notables innovaciones técnicas, supongan, sin discusión, el logro fundamental.

1 MUSSO Y FONTES, J.: Historia de los riegos de Lorca, de los ríos Castril y Guardal, o del Canal de Murcia y de los Ojos de Archivel. Murcia, Imp. José Carles, 1847, p. 11.

2 RAMOS FERNÁNDEZ, R.: «Proyectos para trasvase de aguas de riego a Elche», Cuadernos de Geografia, 1970, núm. 7, p. 260.

3 ALBEROLA ROMA, A.: El pantano de Tibi y el sistema de riegos en la huerta de Alicante. Alicante, Inst. Juan Gil-Albert, 1984, $191 \mathrm{pp}$.

4 LÓPEZ GÓMEZ, A.: «Embalses de los siglos XVI y XVII en Levante», Estudios Geográficos, 1971, núm. 125, pp. 617-656.

5 LÓPEZ GÓMEZ, A.: Els embassaments valencians antics. Valencia, Consellería d'Obres Publiques, Urbanisme i Transports, 1987, p. 10. 
Sin embargo, los reservorios en ríos-ramblas y barrancos del sureste peninsular no acababan de resolver el problema, ya que tenían su función reguladora muy mermada por la propia penuria e irregularidad de las precipitaciones, algunos años poco menos que inexistentes; de ahí que perdurase la necesidad de solventar esta contingencia, causa habitual de la pérdida o drástica disminución de cosechas, con caudales trasvasados de resurgencias copiosas, ríos alóctonos o abundosas cabeceras fluviales. Salvo la apertura del primer tramo del Canal Imperial de Aragón, los restantes proyectos, que apenas pasaron de meros tanteos, tenían por casi únicos objetivos los grandes regadíos deficitarios del sureste peninsular, en particular los de Elche y Lorca.

Durante buena parte del XVI los lorquinos pretendieron la concesión y encauzamiento de las fuentes de Archivel; tres intentos, al menos, se suceden hasta 1566, año en que Caravaca se opuso frontalmente a las aspiraciones conjuntas de Lorca, Murcia y Cartagena sobre dichas resurgencias. El empeño más consistente, frustrado por la sublevación de los moriscos granadinos, se concretó en un Memorial elevado a Felipe II por el toledano Hernán Pérez de Herrera, cuya finalidad radicaba en conducir a Lorca los débitos de las fuentes de Archivel, Venablón, Singla, Barranda, Coneja, Naviales y Ojos de Archivel, con un módulo global próximo a $400 \mathrm{l} / \mathrm{s}$.; dicho plan había merecido informes favorables del ingeniero comisionado por el monarca, así como del corregidor de Murcia y del alcalde mayor de Lorca ${ }^{6}$. Junto a la viabilidad de la iniciativa, es de resaltar asimismo su alcance limitado y la insuficiencia del módulo para cubrir la demanda del regadío lorquino.

El fracaso de las negociaciones con Caravaca para el aprovechamiento de las fuentes propició que adquiriese cuerpo un proyecto mucho más ambicioso, consistente en un trasvase desde las cabeceras de los ríos Castril y Guardal, afluentes del Guadiana Menor que avenan la vertiente meridional de la sierra de Segura; ésta fue la solución propuesta en 1574 por el regidor de la localidad sevillana de Coria Álvaro Rodríguez de Maderuela. Dicha alternativa, muy costosa y plagada de dificultades técnicas, tropezaba, además, con la oposición del duque de Alba, señor de Huéscar y Castril, quien aducía serios perjuicios en ambos dominios, destacando la imposibilidad en que se encontraría de transportar hacia el Guadalquivir las maderadas de sus montes. Así, el último cuarto del XVI conoce el reemplazo de la vieja y razonable idea de utilizar las fuentes de Caravaca por la nueva y perdurable, hasta el siglo actual, del trasvase de los ríos Castril y Guardal?.

En 1575 el arquitecto Gabriel Ruiz Tauste quedó encargado del estudio preliminar y al año siguiente se dispuso que el arquitecto real Gerónimo Gili pasase a examinar el terreno y aforar los ríos, para emitir el oportuno informe; éste resultó por completo negativo, al estimar que existían obstáculos insalvables. La ciudad de Lorca, apoyada por las de Murcia y Cartagena, cuestionó la objetividad del dictamen, que supuso mediatizado por fuertes presiones contrarias a la obra, y reclamó la intervención de otro técnico. Fue éste un desdichado nivelador italiano que, tras un informe favorable, mudó luego de parecer, sin que ello bastase para librarle de las garras del Santo Oficio por «palabras sospechosas que decían haberle oído» ${ }^{8}$.

Reinando Felipe III, el capitán de ingenieros don Pedro Agustín Abarca acudió al monarca para que ordenase la ejecución de los trabajos. Sugirió que el dinero necesario lo aprontase la Real Hacienda, con la compensación de los beneficios, o, como segunda solución, que fuese aportado por los pueblos interesados en forma proporcional al disfrute

6 BAUTISTA MARTÍN, J. y MUÑOZ BRAVO, J.: Las presas del Estrecho de Puentes. Murcia, Confederación Hidrográfica del Segura, 1986, p. 31.

7 BAUTISTA MARTÍN y MUÑOZ BRAVO: Op. cit. p. 31.

8 CÁNOVAS y COBEÑO, F.: Historia de la Ciudad de Lorca. Lorca, Imp. de «El Noticiero», 1890, p. 419. 
del módulo. En 1621 se aprobó la ejecución del plan, y ese mismo año recibió instrucciones el corregidor de Murcia, Cartagena y Lorca para distribuir los 296.000 ducados que importarían las obras; los inconvenientes surgieron a la hora de derramar esa cantidad. El proyecto fue reemprendido en 1629 por la Junta de Población del Reino; en esta ocasión los trabajos llegaron hasta la sierra de Almorox, para quedar detenidos allí por errores técnicos y dificultades de financiación ${ }^{9}$.

En diferentes momentos se ha pensado en conducir a Elche caudales de Villena, del Júcar, del Ebro y hasta de las Lagunas de Ruidera ${ }^{10}$. La idea de transferir agua del Júcar a la cuenca del Vinalopó pervive hoy, con nueva proposición y diferente recorrido; en efecto, desde comienzos del XV el empeño, con diversas versiones, ha reaparecido una y otra vez. Denominador común de las distintas propuestas era el inicio del canal, en uno u otro punto, entre La Roda y Villa Ves, para buscar la gran línea de fractura de los valles de Ayora y del Vinalopó. Resaltemos también, como dato invariable, la sistemástica disconformidad de la Ribera, apoyada por la ciudad de Valencia.

Una Noticia sobre el Canal del Júcar, fechada en 1847, afirma que «en 1568 de orden del Duque de Maqueda, Marqués de Elche, se nivelaron los terrenos por donde podría venir una acequia de agua continua del río Júcar a Elche y en 1628 se trajo la relación y plano a Alicante con el intento de que el agua llegase a ella para lo cual se hicieron nivelaciones y reconocimientos..., pero quedó esto sin efecto a causa de la oposición que hizo la Ciudad de Valencia...» ${ }^{11}$. El proyecto, cuyo coste de ejecución se evaluó en 700.000 ducados, pretendía tomar setecientos de los 2.100 hilos o palmos cuadrados aforados, durante el estiaje de agosto, a la altura del curso donde se practicaría la derivación. El canal, con un desarrollo previsto de 30 a 38 leguas $(165,18-211,76 \mathrm{Km})$, tendría 30 palmos de ancho $(8,34 \mathrm{~m})$ y $20(5,56 \mathrm{~m})$ de profundidad, con tres «puentes acueductos considerables» para salvar otras tantas ramblas procedentes de la sierra de Alcaraz. En su recorrido, la «acequia real» o canal de trasvase regaba en origen una vega del duque de Escalona y luego tierras de La Roda, La Gineta, Albacete, Barrax, Balazote, Peñas de San Pedro, Chinchilla, Jorquera, Carcelén, Ayora, Alpera, Almansa, Caudete y Villena; en este último término el canal vertía a la rambla de Elche o Vinalopó con sangrías para Sax, Elda, Albatera, Crevillente, Elche, Monóvar, Novelda, Aspe, Monforte, Agost y Alicante ${ }^{12}$.

Durante los siglos XVI y XVII los proyectos de trasvase conocieron dificultades generalizadas de carácter técnico y financiero prácticamente invencibles, con otras bien frecuentes de oposición en las áreas que habían de ceder recursos hídricos, sin que faltase asimismo en las propias tierras beneficiadas la enemiga de los dueños de aguas vivas o perennes, que veían amenazado su pingüe negocio de venta en subasta pública del turno de uso de las mismas en cada tanda, tal y como sucedía en los principales regadíos deficitarios del sureste peninsular ${ }^{13}$. Ninguna de las múltiples iniciativas de trasvase surgidas en el sureste peninsular durante ambas centurias se hizo realidad. Los embalses, como solución alternativa, ganaron la partida, si bien, por las razones antedichas, no resolvieron la grave carencia de recursos hídricos, que tan sólo paliaron en mayor o menor grado.

9 GIL OLCINA, A.: El Campo de Lorca. Estudio de Geografía Agraria. Valencia, Dpto. de Geografía y C.S.I.C., 1971, p. 89.

10 RAMOS FERNÁNDEZ, R.: «Proyectos para trasvase de aguas de riego a Elche», Cuadernos de Geografía, 1970, núm. 7, pp. 259-272.

11 «Noticia sobre el Canal del Júcar», 1847 (manuscrito), Canal del Júcar. Archivo M.O.P.U. Alicante.

12 «Noticia sobre el Canal del Júcar», 1847 (manuscrito), Canal del Júcar. Archivo M.O.P.U., Alicante.

13 GIL OLCINA, A.: «La propiedad del agua en los grandes regadíos deficitarios del sureste peninsular: el ejemplo del Guadalentín», Agricultura y Sociedad, 1985, núm. 35, pp. 203-231. Id.: «Propiedad y valor de las aguas del Bajo Vinalopó», Homenaje al Profesor Juan Torres Fontes, 1987, pp. 647-660. 
Una coyuntura distinta, mucho más propicia a las grandes obras hidráulicas, se produjo cuando las actuaciones de raigambre local dieron paso a una política estatal de organización del espacio mediante ordenación del territorio.

\section{Costosos fracasos y notables éxitos hidráulicos del reformismo ilustrado}

Es usual el empleo de una periodización del XVIII español, muy difundida por simple y cómoda, que peca, no obstante, de precaria y fuerza muchos aspectos de una realidad más compleja, entre los que cuenta la política hidráulica del reformismo ilustrado. En esta faceta el citado esquema distingue un período de formación bajo Felipe $\mathrm{V}$, otro de elaboración con Fernando VI, la plenitud de Carlos III y el reinado epigónico de Carlos IV. Sería injusto afirmar que dicha división carece de referencias significativas, si bien magnifica unas y olvida otras; ello mueve al repaso, siquiera sea sumario, de los planteamientos y realizaciones hidráulicas bajo los cuatro primeros monarcas españoles, descontado Luis I, de la Casa de Borbón.

Parece hoy fuera de duda que, cuando se produjo él advenimiento de Felipe V, el cambio de coyuntura, con una perceptible recuperación de la periferia peninsular, había comenzado. Tras el paréntesis del conflicto sucesorio dicha tendencia se confirma y afianza en muy diversos órdenes, si bien perturbada a causa de los enfrentamientos bélicos suscitados, primordialmente, por las ambiciones maternales de Isabel de Farnesio y el irredentismo que auspiciaba Alberoni. En 1749, fallecido ya Felipe V, el preámbulo de las Ordenanzas de Intendentes Corregidores, signadas por Fernando VI, declaraba que: «Cuarenta y ocho años de sangrientas y continuadas guerras que han sufrido mis vecinos y vasallos; la esterilidad y calamidades que han experimentado en tan largo tiempo, por falta de cosechas, comercios y manufacturas; las repetidas quintas y levas... son las causas que han reducido a un deplorable estado de gobierno económico» ${ }^{14}$. Afirmaciones tan concluyentes, acordes con el pacifismo que caracterizaría el nuevo reinado, propugnaban, sin reservas, el olvido de las aventuras internacionales en favor de una política de fortalecimiento y reconstrucción interior, seriamente dificultada hasta entonces por aquéllas.

Salvo algunos logros puntuales, entre los que sobresalen las Pías Fundaciones del Cardenal Belluga en el Bajo Segura y determinados trabajos en el Guadalquivir y Canal Imperial de Aragón, las actuaciones hidráulicas, bajo Felipe V, consisten esencialmente en reconocimientos de terrenos, nivelaciones y confección de mapas; sobresale el interés por el proyecto de trasvase de los ríos Castril y Guardal, viejo empeño, que fue ahora objeto de consideración y estudio por técnicos tan cualificados como Jorge Próspero de Verboom, entre 1718 y 1720 , Sebastián Feringan en 1742 y Vodopich un año después. Es de notar que una Real Orden de 17 de abril de 1711 creó el cuerpo de ingenieros militares y colocó a su cabeza al citado Verboom; a pesar de la naturaleza de aquél, la participación de sus miembros en obras civiles revistió enorme importancia ${ }^{15}$.

El deseo de revitalizar la monarquía y devolverle el lugar perdido en el concierto internacional, evidenció, desde el primer momento, la urgencia de vertebrar el territorio peninsular mediante un adecuado sistema de comunicaciones; planteamiento éste que, tributario del colbertismo y del ejemplo extranjero, sobre todo francés, guió, en gran

14 HELGUERA QUIJADA, J.: «Aproximación a la historia del Canal de Castilla», en El Canal de Castilla, Valladolid, Junta de Castilla y León, 1988, p. 18.

15 CAPEL, H. et alt.: Los ingenieros militares en España. Siglo XVIII. Barcelona, Publicaciones y Ediciones de la Universidad, $496 \mathrm{pp}$. 
medida y mucho tiempo, la política hidráulica de los gobiernos ilustrados, con una amalgama de mercantilismo básico y fisiocracia adicional, aderezado todo con una fuerte dosis de arbitrismo.

Si la Instrucción de Intendentes de 1718 revela ya estas directrices, las mismas se hacen doctrina en Teoría y práctica de comercio y marina (1724) de Jerónimo de Uztariz, cuya influencia se hace sentir en el Restablecimiento de las Fábricas y Comercio Español, publicada en 1740 y cuyo autor, Bernardo de Ulloa, insiste en la necesidad de que se desarrolle la navegación fluvial y se trace una red de canales capaz de superar aislamientos y dañinas desconexiones territoriales. De idéntica opinión era el marqués de la Ensenada, quien, en la famosa representación dirigida, el año 1751, a Fernando VI, argüía: «No hay en Europa terreno más seco que el de España, y por consecuencia están expuestos sus naturales a padecer hambres por sus malas cosechas, ni tampoco Reino en que menos se haya ejercitado el arte para ocurrir a la precisión de socorrer unas provincias a otras, evitando la extracción de dinero a dominios extraños, pues no se ha procurado que sus ríos sean navegables en lo posible, que haya canales para regar y transportar, y que sus caminos sean cual deben y pueden ser. Conozco que para hacer los ríos navegables y caminos son menester muchos años y muchos tesoros; pero, Señor, lo que no se comienza no se acaba, y si el gran Luis XIV prescribió reglas y ordenanzas que siguió y se siguen con tan feliz suceso, ¿por qué no se podrán adoptar y practicar en España siendo V.M. su Rey ?» ${ }^{16}$. Como subraya Helguera ${ }^{17}$, el propósito de Ensenada fue el logro, mediante la mejora de las comunicaciones, de un mercado agrícola nacional para resolver las crisis de subsistencia, que esporádicamente afligían a una u otra provincia, sin acudir a gravosas importaciones; la solución propuesta radicaba en la creación de un entramado suficiente de carreteras y vías fluviales. Si se recuerda el objetivo primordial, no debe extrañar la preferencia por la cuenca del Duero, principal área cerealista; según el plan de obras e inversiones elevado a Fernando VI en 1751, Ensenada trataba de «perfeccionar el camino que llaman de la Montaña, y los exámenes de la posibilidad o imposibilidad de hacer canales en Castilla la Vieja que se den la mano con el referido camino. Si fuere posible esta empresa y se facilitan fondos para ella, conseguiría S.M. dar a sus reinos un tesoro inagotable, porque Castilla la Vieja dará salida, que no tiene, a sus abundantes frutos, que traerán sumas de dinero de reinos extraños; y cuando haya carestía en Andalucía y Murcia, como suele suceder, las socorrerá, quedando en la península los muchos millones de pesos que se llevan los ingleses y otros con los granos que traen a vender» ${ }^{18}$. El pristino designio del Secretario de Estado y Despacho Universal incluía la construcción de caminos que desde Reinosa y El Espinar franquearían respectivamente las cordilleras Cantábrica y Central, para luego unirlos por una red de canales navegables que enlazarían entre sí los mayores núcleos de población; esta última fase resultaba singularmente problemática. Para afrontarla se requirió la colaboración de Antonio de Ulloa, quien eligió al ingeniero francés Carlos Lamaur para redactar el proyecto.

Tras numerosas vicisitude ${ }^{19}$, entre ellas la inteligente iniciativa de Lemaur de utilizar los canales para navegación y riego, Antonio de Ulloa, teniendo por base los trabajos del primero y sus propias observaciones, confeccionó, en 1753, un Proyecto General de los Canales de Navegación y Riego para los Reinos de Castilla y León, al que se atuvieron, con pocas variantes, las obras ejecutadas en ese ámbito durante la segunda mitad del

16 HELGUERA QUIJADA: Op. cit., pp. 18-19.

17 HELGUERA QUIJADA: Op. cit., pp. 17-21.

18 HELGUERA QUIJADA: Op. cit., p. 20.

19 HELGUERA QUIJADA: Op. cit., pp. 21-78. 
$\mathrm{XVIII}^{20}$. Añadamos que el ambicioso programa de navegación fluvial elaborado bajo Fernando VI no se circunscribía únicamente a la cuenca del Duero sino que afectaba asimismo a los ríos Ebro, Guadalquivir y Tajo ${ }^{21}$.

En consecuencia, al suceder en el trono a su hermano, Carlos III encontró no sólo estudios y proyectos sino obras en trance de ejecución. Continuaron los trabajos en los Canales de Campos y Castilla: la construcción del ramal norte, comenzada en 1759, concluiría, ya desaparecido el monarca, en 1791; mientras, el canal sur, iniciado el mismo año, no se terminaría, con una interrupción que se alargó de 1804 a 1831, hasta 1835 . Aún después, en 1849, finalizaría el Canal de Campos ${ }^{22}$. Tampoco faltaron problemas, sobre todo de orden financiero, para la prolongación del Canal Imperial de Aragón, llevada a feliz término por la excelente gestión del canónigo Pignatelli, nombrado Protector del mismo ${ }^{23}$; con el Canal Imperial guardan relación el de Tauste, cuya finalidad primordial es el riego, y el de navegación entre Amposta y los Alfaques.

Fracasos rotundos y clamorosos constituyeron, en cambio, empresas tan desmesuradas y quiméricas como los canales de Murcia y Guadarrama. La denominada Compañía del Canal de Murcia pretendía construir un «Canal de Riego y Navegación, con las Aguas de los Ríos Castril, Guardal y otros, para que se puedan regar, y hacer fecundos los campos de Lorca, Totana, y demás del Reyno de Murcia, en la forma que se expresa. Año de $1774 \gg^{24}$.

El plan perseguía el aprovechamiento integral y conjunto de las cabeceras del Castril y Guardal, cuenca alta del Guadalentín y fuentes de Archivel. La infraestructura precisa para llevarlo a cabo principiaba en el nacimiento del Castril, que se uniría al del Guardal por una mina de $10 \mathrm{Km}$ en Sierra Seca; ambas cabeceras quedarían reguladas por sendas presas, al igual que la fuente baja del Guardal, punto de partida del canal de riego y navegación que, con anchura de 20 pies $(5,57 \mathrm{~m})$ y $8(2,23 \mathrm{~m})$ de profundidad, había de recorrer 43 leguas $(287 \mathrm{Km})$ hasta Cartagena, en cuyo campo se bifurcaba en un ramal, tan sólo para riego, que moría en el Mar Menor y otro, que era además navegable, hasta Cabo de Palos. Para proporcionar idea, siquiera sea aproximada, del gigantesco sistema proyectado baste mencionar las 92,75 leguas $(620 \mathrm{Km})$ de la red de canales, la realización de esclusas, grandes acueductos y largos túneles, el mayor de los cuales perforaba 13,4 Km en Sierra de Topares, y, sobre ello, la construcción de los embalses de Valdeinfierno, Agua Amarga y Puentes. Como notoria excepción, la finalidad primordial del canal era la ampliación y mejora de regadíos, con una superficie afectada de 300.000 fanegas de 4.000 varas cuadradas, equivalentes a 84.000 hectáreas; no se descuidaba por ello la navegación, que permitiría el transporte de maderas y producciones agrícolas desde el noreste de la provincia de Granada al Mediterráneo y, a partir de éste, en sentido ascendente, la importación de mercancías.

Luego de revocar, en 1776, una concesión a particulares por incumplimiento de condiciones, el gobierno creó la Real Compañía del Canal de Murcia, cuyos recursos para la financiación de las obras procedían de la renta de Correos, arbitrio sobre vinos y aguardientes

20 HELGUERA QUIJADA, J.: «El Canal de Castilla como factor de desarrollo económico regional en el siglo XVIII», en El pasado histórico de Castilla y León. Burgos, Junta de Castilla y León, II, pp. 493-515.

21 ALZOLA Y MINONDO, P.: Historia de las obras públicas en España, 1899, (Ed. facsímil), Madrid, Colegio de Ingenieros de Caminos, Canales y Puertos y Ediciones Turner, 1979, 504 pp. DÍAZ-MARTA PINILLA, M.: «Realismo y utopía en los proyectos hidráulicos de la Ilustración y el Romanticismo», en Planos históricos de obras hidráulicas. Madrid, Servicio de Publicaciones del M.O.P.U., 1985, pp. 10-27.

22 LLAURADO, A.: Tratado de Aguas y Riegos. Madrid, Imp. Moreno y Rojas, 1884, 2. ed., II, p. 32.

23 FERNÁNDEZ MARCO, J. I.: El Canal Imperial de Aragón. Estudio Geográfico. Zaragoza, Junta del Canal Imperial de Aragón y Dpto. de Geografía Aplicada del Inst. «Juan Sebastián Elcano», 1961, 180 pp.

24 MULA GÓMEZ, A. J.; HERNÁNDEZ FRANCO, J. y GRIS MARTÍNEZ, J.: Las obras hidráulicas en el reino de Murcia durante el reformismo borbónico. Murcia, Colegio de Ingenieros de Caminos, Canales y Puertos, 1986, $268 \mathrm{pp}$. 
e impuestos sobre barrilla, sosa y esparto. Aún hoy impresionan las excavaciones y demás trabajos efectuados entre 1776 y $1780^{25}$. Pronto surgieron, empero, certezas negativas y dudas; las primeras se referían a la insuficiencia de los caudales disponibles y las segundas, aún más graves, a la propia viabilidad del canal. Una Rea! Orden de 24 de marzo de 1778 marginó la navegación y convirtió el riego en única meta. Otra Real Orden dispuso, el 8 de octubre de 1780 , una minuciosa supervisión del proyecto y obras ejecutadas por una amplia comisión de afamados ingenieros y arquitectos, cuyo informe hizo notar la existencia de obstáculos insuperables; la realidad acabó por imponerse a la utopía cuando el Real Decreto de 11 de febrero de 1785 disolvió la Compañía del Real Canal de Murcia. Poco antes un arquitecto autodidacta, Jerónimo Martínez de Lara, miembro de la citada comisión, había elevado a Carlos III un memorial en el que, como solución alternativa, si bien de alcance muy inferior, proponía la construcción de dos presas, cuestión sobre la que, por su enorme trascendencia, volveremos después ${ }^{26}$.

Empresa aún más desmesurada y fantástica que el Real Canal de Murcia fue el llamado Canal de Guadarrama al Océano, denominación debida a que, según el proyecto elaborado por el ya brigadier general de ingenieros Carlos Lemaur y sus hijos, dicha vía, luego de seguir los valles del Manzanares, Jarama y Tajo, atravesaría la Mancha y Sierra Morena hasta el Guadalquivir y, por el sur de éste, alcanzaría Sevilla y el mar. Como señala López Gómez, comenzados los trabajos de Guadarrama en 1787, perduraba la idea originaria, de manera que, el 19 de julio de 1788, la Junta del Banco de San Carlos informa a Floridablanca que el canal de Guadarrama a Sevilla, a concluir en 16 ó 18 años, costaría 217 millones de reales $^{27}$. La primera fase del proyecto incluía la colosal presa de la Peña o del Gascó, con vaso de $22,5 \mathrm{Hm}^{3}$ y dique de 327,11 pies $(91,13 \mathrm{~m})$ de altura, y el canal correspondiente, que, con una longitud de 42.953 varas $(35,904 \mathrm{Km}), 8$ varas de ancho en el fondo y 14 en la parte superior $(6,68 \times 11,70 \mathrm{~m})$, salvaba la diferencia de 545 pies $(151 \mathrm{~m})$ de altitud entre el embalse y el canal del Manzanares mediante diecisiete esclusas ${ }^{28}$. En abril de 1796 el muro del pantano se elevaba a unos cincuenta metros y se habían ejecutado $27 \mathrm{Km}$ de canal, con 57 acueductos, algunos con más de ocho metros de altura. Tres años después se produjo el desprendimiento en el dique, que determinaría, luego del gasto de quince millones de reales, la paralización y abandono de las obras.

Más allá de utopías como las del Canal de Murcia y Canal de Guadarrama al Océano, abundaron planteamientos puramente imaginarios y quiméricos. Tan desmedida fue la afición del reformismo ilustrado a los grandes canales que Cadalso hizo a sus proyectistas prototipo de arbitristas y los ridiculizó en el célebre pasaje de sus Cartas Marruecas ${ }^{29}$. Arroyo Ilera y Camamero Bullón han valorado lo que había en éstos, más que designios, sueños ilustrados de intentos de organización del espacio mediante la ordenación del territorio, de configuración y desarrollo de un sistema de comunicaciones más integrador, así como de potenciación de recursos naturales ${ }^{30}$. Resultan evidentes dos errores trascendentales de los gobernantes y técnicos de la época: uno, esencial, de naturaleza geográfica, condujo a extrapolaciones erróneas y originó el espejismo de implantación en la península ibérica de

25 BAUTISTA MARTÍN y MUÑOZ BRAVO: Op. cit. pp. 47-115.

26 GIL OLCINA, A.: «Los pantanos de Puentes y Valdeinfierno», Agua, riegos y modos de vida en Lorca y su comarca, Murcia, CAAM, 1986, pp. 105-120.

27 LÓPEZ GÓMEZ, A.: «La presa y el canal del Guadarrama al Guadalquivir y al Océano, una utopía fallida del siglo XVIII», Boletín de la Real Academia de la Historia, T. CLXXXVI, Cuaderno II, p. 238.

28 LÓPEZ GÓMEZ: Op. cit. 27, p. 242.

29 CADALSO, J.: Cartas Marruecas (Selección, estudio y notas por J. Tamayo y Rubio), Zaragoza, Ed. Ebro, 1961, pp. 72-73.

30 ARROYO ILERA, F. y CAMARERO BULLÓN, C.: «Proyectos ilustrados de navegación fluvial», en Los paisajes del agua, Universidades de Valencia y Alicante, 1989, pp. 347-370. 
un sistema de transporte fluvial similar al que poseían otros países europeos de características físicas muy diferentes; y el segundo consistió en el vano intento de reunir en un solo proceso las políticas hidráulica y de navegación interior, postergando, casi siempre, la primera y supeditándola a la segunda.

En resumidas cuentas, motivaciones mercantilistas y fisiocráticas, impregnadas de una fuerte dosis de arbitrismo, desencadenaron una auténtica «fiebre de canales», con empresas desmedidas e ilusorias, si bien es de destacar que los más trascendentales y trágicos fracasos del reformismo ilustrado se produjeron, por impericia e imprudencia técnica, en la construcción de gigantescos embalses, aunque hay elementos de juicio suficientes para afirmar, sin reservas, que a finales del XVIII la ingeniería hidráulica española era capaz de acometer obras de esa envergadura. El desprestigio de las mismas, a raíz del abandono de la presa del Guadarrama, de la ruina del denominado Mar de la Cabina, del terraplenamiento de Valdeinfierno y, sobre todo, del desastre de Puentes, fue completo. La resonancia de la catástrofe originada por la rotura de este último pantano, con un balance de 608 víctimas y daños estimados en 34.365 .850 reales, fue inmensa, rebasó las fronteras y retrasó sensiblemente la realización de grandes reservorios en todo el ámbito mediterráneo ${ }^{31}$. Juicios adversos sobre esta clase de embalses, con referencia básica a Puentes, menudean entre los tratadistas de aguas hasta comienzos del siglo actual. Todavía en 1904 Brunhes señalaba: Qui tente trop et dépasse la mesure correspondent aux conditions naturelles empire la situation au lieu de l'améliorer. Les exemples de Lorca... ${ }^{32}$. La creación de la Escuela de Ingenieros de Caminos y Canales, en Madrid, con fecha 1 de noviembre de 1802, no es ajena al desastre de Puentes, acaecido el 30 de abril de 1802 y sobre el que informó certeramente al Consejo de Castilla Agustín de Betancourt en 16 de julio del mismo año ${ }^{33}$. Sería este mismo ingeniero quien, en su calidad de Inspector General de Caminos y Canales, estableciese un esclarecedor balance de la política de obras públicas del reformismo ilustrado en su célebre Noticia del estado actual de los caminos y canales en España, causas de sus atrasos y defectos y medio de remediarlos en adelante.

\section{Legislación decimonónica de aguas: concesiones y usos}

El colosal esfuerzo de los gobernantes ilustrados en materia de obras hidráulicas se saldó con resultados poco alentadores. Planteamientos utópicos o impericias se tradujeron en fiascos antológicos. Cuando Betancourt se preguntó «¿qué proyectos, qué cálculos ni qué aciertos se podrían esperar de la clase de estudios que han hecho la mayor parte de los sujetos que hasta ahora se han empleado en estas obras públicas, ni qué medios se han puesto para facilitar la instrucción de unas personas en quienes se depositan los intereses, la seguridad, la confianza y una gran parte de la prosperidad de la nación ? $^{34}$, muy posiblemente tenía presente la impar catástrofe de Puentes y a su director, el autodidacta

31 GIL OLCINA, A.: «Los embalses de Puentes y Valdeinfierno (Contribución al estudio de las obras hidráulicas en España)», Actas del III Congreso de Historia de la Medicina y de la Ciencia, Valencia, 1977 , pp. 277-286.

32 BRUNHES, J.: L'irrigation, ses conditions géographiques, ses modes et son organisation dans le Péninsule Ibérique et dans l'Afrique du Nord. Paris, 1904, pp. 143 y 432.

33 MULA GÓMEZ; HERNÁNDEZ FRANCO y GRIS MARTÍNEZ: Op. cit., pp. 234-239.

34 BETANCOURT, A. de: «Noticia del estado actual de los Caminos y Canales de España, causas de sus atrasos y defectos y medio de remediarlos en adelante», (Textos seleccionados por Fátima Miranda Regojo), en BONET CORREA, A.; MIRANDA F. y LORENZO, S.: La polémica ingenieros-arquitectos en España, siglo XIX. Madrid, Colegio de Ingenieros de Caminos, Canales y Puertos, 1985, p. 135. 
Martínez de Lara ${ }^{35}$. Añadamos, empero, por estricta justicia, que los más ambiciosos y desmesurados proyectos, como el Canal de Murcia o el de Guadarrama, fracasaron en manos y bajo las directrices de reputados técnicos extranjeros. En resumidas cuentas, concluido el XVIII, el afanoso empeño en el desarrollo de las comunicaciones fluviales, la ampliación y mejora del regadío, así como el aprovechamiento de la energía hidráulica, distaban mucho de alcanzar niveles satisfactorios.

A pesar de la esperanzadora apertura de la Escuela de Ingenieros de Caminos y Canales, los primeros lustros de la nueva centuria no resultaron nada propicios a rectificaciones o innovaciones en política hidráulica. Acontecimientos internacionales de excepcional magnitud reclamaron todas las energías y consumieron los recursos, generando una deuda pública de cifras astronómicas; fue, primero, la lucha contra la Convención, luego el conflicto con Inglaterra y, por último, la invasión francesa. Tras la prolongada guerra napoleónica, con su incalculable y pesadísimo lastre de destrucciones, España era un país arruinado, cuya reducción a potencia de segundo orden vendría confirmada por la emancipación iberoamericana.

El retorno de Fernando VII no ayudó mucho a la paz interior y a la reconstrucción nacional, más bien todo lo contrario. Anécdota es, aunque no por ello menos expresiva, que el monarca disolvió en 1814 el Cuerpo de Ingenieros, con muchos de sus miembros sañudamente perseguidos por liberales, y clausuró la Escuela de Caminos, cuyas instalaciones del Buen Retiro fueron ocupadas por una Escuela de Tauromaquia ${ }^{36}$. Con este sombrío panorama de enfrentamiento intestino y erario exhausto, las obras hidráulicas fueron reemprendidas por la iniciativa privada, que reemplazaba por entero la acción pública, trabada por necesidades perentorias de toda índole y carencia de recursos. Dicha situación tuvo amplio y creciente reflejo en una legislación que amparaba y propiciaba el régimen de concesiones.

Un real decreto de 19 de mayo de 1816 concedía exención del aumento de diezmos y primicias que resultaran de la transformación en regadío. De parecido tenor es otro real decreto de 31 de agosto de 1819 , que otorgaba esa franquicia por tiempo de doce años a quienes aplicasen aguas a riego o ejecutasen canales de regadío «ya tomen las aguas de los ríos, ya las reúnan de muchos arroyos o manantiales, o las extraigan del seno de altas montañas». Tras un largo paréntesis sin disposiciones de importancia en este aspecto, una real orden de 4 de agosto de 1833, que versaba sobre aprovechamientos en el río Guadalhorce, reconocía, con carácter general la conveniencia y necesidad de reglas precisas sobre concesiones de caudales a expensas de ríos y manantiales ${ }^{37}$. Dicha preocupación encontraría espléndida y cumplida respuesta en la segunda mitad de siglo, etapa singularmente fecunda para la consolidación del derecho de aguas en España.

Entre sus hitos más notorios cuenta la Ley sobre Dominio y Aprovechamiento de Aguas que, promulgada el 3 de agosto de 1866, constituye el primer código español y europeo sobre dicha temática. Poco después esta disposición fue sensiblemente modificada por el importante decreto-ley de bases para la legislación de obras públicas de 14 de noviembre de 1868 y la ley de 20 de febrero de 1870 relativa a la construcción de canales de riego y pantanos, esta última acompañada de un interesante reglamento; dichas disposiciones reflejan un espíritu intensamente descentralizador y de libertad económica.

Aspecto importante es la duración de las concesiones, que el decreto ley de bases para

35 ESPIN RAEL, J.: El arquitecto Martínez de Lara y el famoso Pantano de Lorca. Madrid, 1926.

36 BONET CORREA; MIRANDA y LORENZO: Op. cit., p. 19.

37 GIL OLCINA, A.: «Embalses españoles de los siglos XVIII y XIX para riego», Estudios Geográficos, 1972, núm. 129, pp. 560-564. 
la legislación de obras públicas de 14 de noviembre de 1868 fija, salvo casos excepcionales, en un máximo de noventa y nueve años, criterio que será mantenido por la Ley de Aguas de 1879. En cambio, la Ley sobre Canales de Riego y Pantanos, cuyo inspirador fue Echegaray, no establecía límite temporal, dentro de una tónica excepcionalmente favorable a la iniciativa privada; como evidente muestra de ello puede indicarse el artículo octavo, redactado en los términos siguientes: «Además de la perpetuidad de las concesiones, de la libertad para establecer y modificar el canon o renta, y de cuantos derechos otorga la legislación vigente a las empresas de canales, riegos y pantanos se les concede el importe del aumento de la contribución que se ha de imponer a los dueños de las tierras regadas hasta completar la suma de 150 pesetas/hectárea ${ }^{38}$. En la legislación posterior, si bien perdura esta actitud muy favorable a la iniciativa privada, tal y como se observa, por ejemplo, en la denominada Ley Gamazo, de 27 de julio de 1883, aparecen algunas restricciones respecto de la anterior, que llegaba a otorgar derecho automático de expropiación forzosa a los canales y embalses que atendiesen un mínimo de doscientas hectáreas. En definitiva, el régimen de concesiones, muy operativo en esta centuria, dispuso de amplio respaldo legal.

La supeditación del riego a la navegación fluvial, tan cara a los ilustrados, perduró, en gran medida, hasta el último cuarto del XIX, como evidencian algunos datos, espigados entre otros muchos. Así, por ejemplo, una real orden de 30 de julio de 1868 declaraba la navegación del Guadalquivir servicio preferente a los regadíos que pudieran crearse a partir del propio río o de sus afluentes ${ }^{39}$. Todavía en 1884 Llauradó escribía del Canal de Castilla que el empleo de sus aguas, «con aplicación al riego de las tierras, es tan sumamente limitado, que casi puede considerarse como nulo. Esta línea hidrográfica se explota como canal de navegación, haciéndose ésta en barcos, que transportan por término medio 33 $\mathrm{Tm} »^{40}$. Como una muestra más, la Real Compañía de Canalización del Ebro, que había logrado la concesión con el doble objetivo de navegación y riego, descuidó este último, «que debió ser desde un principio objeto esencial de la empresa y que fue mirado, por el contrario, con la mayor indiferencia para buscarse tan sólo el humo de los barcos», si bien la competencia del ferrocarril obligó a modificar radicalmente dicho planteamiento, al extremo que el regadío se convirtió no ya en finalidad prioritaria sino exclusiva ${ }^{41}$. Esta evolución fue muy posterior en el Canal de Castilla; a pesar del decidido propósito estatal, desde comienzos de este siglo, de convertirlo básicamente en canal de regadío, la competencia de usos no se decidió a favor de la agricultura hasta 1947, cuando los ingresos de esta procedencia privaron sobre los obtenidos por navegación ${ }^{42}$.

Más que con dificultades técnicas, que tampoco faltaron, las realizaciones o proyectos hidráulicos decimonónicos, habitualmente a cargo de empresas concesionarias, tropezaron con carencia de recursos económicos o planes de financiación de marcado carácter especulativo. A pesar de condicionamientos políticos o económicos nada propicios, el balance dista mucho de ser desdeñable, gracias, sobre todo, a la iniciativa privada. Durante el siglo XIX concluyen, entre otras, las obras, desarrolladas total o parcialmente en la centuria, de los canales de la izquierda y derecha del Llobregat, Urgel, derecha en el delta del Ebro, Guadiaro, Henares, Castilla, Esla y Duero. Hay que mencionar asimismo proyectos de

38 SALETA, J. M.: Tratado de aguas, expropiación forzosa, obras públicas, agricultura y colonias agrícolas, Madrid, 1879.

39 LLAURADO: Op. cit., II, p. 142.

40 LLAURADO: Op. cit.: II, p. 32.

41 LLAURADO: Op. cit.: II, p. 396, t. II, p. 39.

42 HELGUERA QUIJADA: Op. cit, pp. 151-162. 
trasvase como los del Júcar-Vinalopó o Castril y Guardal-Guadalentín, que no pasaron de la condición de tales.

En conjunto, los canales de navegación o mixtos atrajeron la atención de negociantes y financieros mucho más que los dedicados sólo a riego. Algo similar ocurrió con los grandes embalses, que, en entredicho y desprestigiados por los motivos ya expuestos, no fueron valorados, con alguna excepción, precisamente errónea, como inversiones de alta rentabilidad hasta el último cuarto del XIX. En este ambiente nada favorable sólo situaciones meteorológicas muy adversas son capaces de superar las suspicacias e inercias del mundo agrario; durante la segunda mitad, con un marco legal propicio y notorios avances de la técnica constructiva, las causas inmediatas del proyecto o construcción de un pantano son también circunstancias climáticas muy desfavorables; a la famosa «seca de cuatro años» (1875-1879) que padeció gran parte del país se vinculan estrechamente una serie de pantanos, y, en especial, la reconstrucción de Puentes. También por la misma época se pretenden edificar el de Gestalgar en el Turia y, para la cuenca del Ebro, los de Caspe y Matarraña y se levantan los de Ejea de los Caballeros, Híjar y Grajera ${ }^{43}$.

\section{Plan Nacional de Obras Hidráulicas: Mejora y Ampliación de los Riegos de Levante}

Las ansias reconstructoras que informan el movimiento regeneracionista, los estudios del ingeniero Ramón García, las predicaciones de Joaquín Costa, las campañas del periódico «El Imparcial», la actuación del ministro Gasset, el plan básico de 1902, el de 1909, el Plan Extraordinario de Obras Públicas suscrito, en 1916, por el propio Gasset, parte correspondiente del proyecto de Ley de Fomento de la Riqueza Nacional de 1919, las importantes realizaciones de la Dictadura de Primo de Rivera, con Guadalhorce en Fomento, la ingente labor de Lorenzo Pardo y el encomiable trabajo de las Confederaciones Hidrográficas, constituyen los antecedentes obligados del magno I Plan Nacional de Obras Hidráulicas, publicado en 1933 y del que fue alma el ya mencionado Manuel Lorenzo Pardo, cuya singular personalidad reclama aquí, aunque resulte obligadamente muy breve, escueto apunte biográfico.

Ingeniero en 1906, ejerció como tal en la cuenca del Ebro, de cuya Confederación fue nombrado director técnico en 1926. Intervino decisivamente, con el apoyo de Calvo Sotelo y Guadalhorce, en la espectacular ampliación de los regadíos aragoneses, publicó varios libros y una serie de artículos en «El Sol» sobre sus trabajos y planteamientos. Gozaba de máximo y justificado prestigio cuando Álvaro de Albornoz decretó su cese; afortunadamente, poco después, Prieto le confirió la dirección del Centro de Estudios Hidrográficos y, ya en el bienio cedista, Guerra del Río le nombró Director General de Obras Hidráulicas, cargo en el que dio cima al Plan Nacional. Al término de la guerra civil, dicho plan constituyó directriz básica de la política hidráulica y Manuel Lorenzo ocupó, en 1948, la presidencia del Consejo de Obras Públicas ${ }^{44}$. Este último dato, con frecuencia desconocido o velado, ha de tenerse muy en cuenta a la hora de entender la vigencia ulterior de las ideas contenidas en el I Plan Nacional de Obras Hidráulicas.

Dicho Plan poseía la enorme ventaja de ser organizado, sistemático y coordinado; en ello radicaba su incontestable superioridad sobre el formulado en 1902, que, a pesar del evidente mérito de su carácter pionero, «fue un catálogo de canales y pantanos, casi todos

43 GIL OLCINA: Op. cit. 37 , p. 561.

44 LÓPEZ PIÑERO, J. M. et alt.: Diccionario histórico de la ciencia moderna. Barcelona, Ediciones Península, 1983, I, pp. 546-548. 
ellos aislados, sin relación alguna, aun dentro de la propia cuenca... $\gg^{45}$. Como prueba notoria de este aserto ađucía Lorenzo Pardo el tratamiento dispensado al área mediterránea, «en la región clásica del regadío, donde se sufren las mayores penurias y se alcanzan los mayores beneficios, apenas hay una obra incluida $\gg^{46}$. Objetivo de primer orden en el I Plan Nacional de Obras Hidráulicas era la corrección del desequilibrio hidrográfico entre las vertientes atlántica y mediterránea, mediante los oportunos trasvases. Insistía Lorenzo Pardo en la necesidad de conceder preferencia a las comarcas exportadoras, y reiteraba que «la zona verdaderamente apta para el cultivo de regadío es la mediterránea, donde se conservan los usos más antiguos, las tradiciones más vivas, las instituciones de riego más firmes, las prácticas más sabias, la mayor y más generalizada experiencia». La corrección del desequilibrio hidrográfico se concretaba esencialmente en el Plan de Mejora y Ampliación de los Riegos de Levante, que preveía la transformación de 338.000 hectáreas en las provincias de Murcia, Valencia, Alicante, Almería, Albacete y Cuenca y estimaba necesarios $2.297,16 \mathrm{Hm}^{3}$ anuales para atender dicha superficie y suplementar la dotación de regadíos deficitarios; este volumen había de reunirse con sobrantes de los ríos Mijares, Turia, Júcar, Segura y algunos autóctonos, a los que se añadirían las aguas trasvasadas de las cabeceras del Tajo y Guadiana ${ }^{47}$. En realidad, la toma del Tajo constituía la aportación básica para la corrección del desequilibrio hidrográfico preconizada por Lorenzo Pardo. Sin embargo, dicho empeño, costosísimo y con enormes dificultades técnicas, habría resultado por entonces, aun sin la guerra civil, inviable; recordemos, además, que el complejo Entrepeñas-Buendía y el embalse de Alarcón $\left(1.112 \mathrm{Hm}^{3}\right.$ ), vitales para el proyecto, no fueron realidad hasta esta segunda mitad de siglo.

Por más que el trasvase no dejara de ser un desideratum continuo de los agricultores del sureste peninsular, transcurrieron treinta y cinco años hasta el inicio de las obras en 1968, y, después, otros diez largos hasta que, por fin, las aguas del Tajo alcanzaron el Segura. Durante el intervalo la idea axial del trasvase se mantuvo viva como posible gran solución y de ella se hicieron eco publicaciones diversas. Incluso, respetando sus fundamentos, se formularon algunas variaciones alternativas; así Sánchez Cuervo ${ }^{48}$, para no comprometer los caudales del Júcar y evitar dificultades adicionales, propuso la conducción del Tajo al Segura por una canalización independiente de aquél.

Proyecto asimismo grandioso fue el elaborado por el ingeniero Félix de los Ríos, en 1937, sobre «Aprovechamiento de parte de las aguas sobrantes del Ebro en ampliar y mejorar los riegos de Levante», hecho público el mismo año con evidente finalidad de propaganda política ${ }^{49}$.

La Memoria Adicional al Plan General de Obras Hidráulicas, incluida en el Plan Nacional de Obras Públicas de 1940, concluía que «todo lo planeado hasta ahora no tiene más carácter que el de ideas lanzadas, cuya posibilidad de ejecución hay que demostrar mediante estudios mucho más amplios $»^{50}$. Añadamos que, por entonces, no se había descartado aún el trasvase de parte del débito de los ríos Castril y Guardal a la cuenca del Guadalentín; lejos de ello, entre 1928 y 1942 se redactaron cuatro proyectos que contemplaban, entre otras, dicha finalidad ${ }^{51}$. Todavía en 1960, con ocasión del Plan de Mejora del

45 LORENZO PARDO, M.: «Exposición General», I Plan Nacional de Obras Hidráulicas, I, p. 20.

46 LORENZO PARDO: Op. cit., I, p. 22.

47 L.ORENZO PARDO: Op. cit., I, pp. 196-201.

48 TORRES, Manuel de: El regadio murciano, problema nacional. Murcia, I.O.A.T.S., 1959, 68 pp.

49 RÍOS, F. de los: Aprovechamiento de parte de las aguas sobrantes del Ebro en ampliar y mejorar los riegos de Levante, 1937 (copia). En poder de Antonio Gil Olcina, Lorca.

50 Plan general de obras públicas hidráulicas. Memoria Adicional. Madrid, 1940, pp. 85 y ss.

51 BAUTISTA MARTÍN y MUÑOZ BRAVO: Op. cit., p. 62. 
Regadío de Lorca, el Centro de Estudios Hidrográficos examinó, por última vez, y desechó dicha alternativa a causa de la falta de regulación de las cabeceras de aquellos ríos, que ya se ha producido mediante los embalses del Negratín $\left(546 \mathrm{Hm}^{3}\right)$ y San Clemente $\left(120 \mathrm{Hm}^{3}\right)$, y a la opción de alcance muy superior que representaba el trasvase Tajo-Segura. Este se haría finalmente realidad, auspiciada la decisión por una serie de estudios y la dura sequía que sufría en 1967 la cuenca del Segura.

En esencia, el sistema consiste en un canal de 286 kilómetros de longitud y $33 \mathrm{~m}^{3} / \mathrm{s}$. de gasto que arranca del pantano de Bolarque, aguas abajo de Entrepeñas-Buendía, llega al de Alarcón y desde allí al embalse de Talave en el río Mundo. Entre sus instalaciones más notables figuran una central reversible de bombeo encargada de salvar un desnivel de 210 metros, dos grandes acueductos para cruzar los lechos mayores del Zancara y Cigüela con longitudes respectivas de 2,893 y 6,277 kilómetros, y, sobre todo, el túnel del Talave, con 31,4 kilómetros a profundidades entre 200 y 300 metros, cuya perforación resultó muy penosa no sólo por la descomunal longitud sino a causa de su inundación por copiosas aguas hipogeas. Destaquemos asimismo la costosísima infraestructura del postrasvase, cuya red de distribución, articulada sobre los canales de la margen izquierda (Vega Baja, Bajo Vinalopó y Campo de Cartagena) y margen derecha (cuencas de los ríos Mula, Guadalentín y Almanzora) totaliza 232 kilómetros.

El Anteproyecto General de Aprovechamiento Conjunto de los Recursos Hidráulicos del Centro y Sureste de España, Complejo Tajo-Segura establecía como objetivo final el trasvase de $1.000 \mathrm{Hm}^{3}$ anuales, de ellos 640 con destino a riego. Dicha meta se alcanzaría en dos fases, con una primera de $600 \mathrm{Hm}^{3}$. Se contaba con transformar en regadío 90.000 hectáreas y completar las asignaciones de 46.816 deficitarias. Sin embargo, el desarrollo de la primera fase ha tropezado con serias dificultades políticas, hasta el extremo que el año hidrológico con mayores transferencias $\left(344,6 \mathrm{Hm}^{3}\right.$, en 1981-82) no ha rebasado mucho la mitad del tope previsto.

El volumen anual calculado para esta primera etapa se repartía entre riegos $\left(400 \mathrm{Hm}^{3}\right)$ y abastecimientos $\left(110 \mathrm{Hm}^{3}\right)$, con unas pérdidas estimadas en $90 \mathrm{Hm}^{3}$. Para abastecimientos se destinan actualmente más de $110 \mathrm{Hm}^{3}$, excedida, con creces, la consignación originaria. En consecuencia, la reducción efectiva del trasvase ha afectado primordialmente al regadío, cuya dotación puede considerarse disminuida, por término medio, en este primer período, en sus dos terceras partes.

Resulta, empero, paradójico que, si se comparan las superficies regadas para 1976 en el ámbito del trasvase con las actuales, los objetivos agrícolas parecen milagrosamente cumplidos, ya que la extensión beneficiada sube a 135.361 hectáreas frente a las 136.816 previstas. Basta una simple ojeada al mapa de regadíos del Segura elaborado por la Dirección General de Obras Hidráulicas en 1983 o la mera confrontación de superficies regadas en 1967 y 1980 para deshacer el equívoco; la conclusión inmediata es que los nuevos regadíos emplean recursos mixtos o subterráneos y la ampliación de los mismos se había producido ya casi en su totalidad antes de la llegada del trasvase. El extraordinario volumen de recursos hipogeos bombeados y, en grado muy inferior, el desarrollo de riegos localizados explican el aparente milagro, con serios riesgos y equilibrio muy inestable, sostenido gracias a que alguna temporada extraordinariamente lluviosa atenúa los efectos de una dañina sobreexplotación y prorroga la existencia de acuíferos exhaustos, si éstos no han experimentado un deterioro definitivo.

Al margen de cualquier polémica, cabe la afirmación, difícil de cuestionar, de que las mermadísimas transferencias del Tajo son en el reseco sureste incomparablemente fecundas, no sólo por su elevado rendimiento agrícola sino como vital contribución a las demandas urbana, industrial y turística de recursos hídricos que satisface la Manco- 
munidad de los Canales del Taibilla, a la que proporcionan un $60 \%$ de su gasto ${ }^{52}$.

\section{Planificación hidrológica y transferencia de recursos hídricos en la actual Ley de Aguas}

El litoral mediterráneo español ofrece casos muy diversos de demanda y aprovechamiento de caudales foráneos. Citemos, como muestra, el empleo de los débitos extraídos del acuífero Guadalentín-Biznaga en el litoral murciano de Águilas, la aspiración alicantina, ahora con nuevo planteamiento, al trasvase de sobrantes del Júcar y, por último, las distintas solicitudes que gravitan sobre el Ebro; dichos casos ejemplifican tres escalas diferentes, comarcana la primera, interprovincial en el seno de una misma comunidad autónoma la segunda, mientras la última involucra, al menos, nueve comunidades autónomas.

Ante la extremada penuria de disponibilidades hídricas, sin participación prevista en el trasvase Tajo-Segura y con el incentivo de los altos rendimientos de una agricultura de vanguardia centrada en el tomate de invierno, las empresas más importantes, la mayor sociedad agraria de transformación existente en el municipio y el propio Ayuntamiento de Águilas, que debía responder a un crecimiento muy acelerado del consumo urbano por la afluencia turística estival, decidieron en los años setenta utilizar aguas extraídas en la parte alta de la Depresión Prelitoral Murciana. El uso de éstas requería, en primer lugar, adquirirlas, por uno u otro procedimiento, y luego trasvasarlas a la franja costera, franqueando, mediante bombeo o trazado de gravedad, la sierra de Almenara. No ha existido plan de conjunto; son seis las conducciones procedentes de la Depresión Prelitoral y la mayor de ellas, a pleno rendimiento, posee un gasto de $350 \mathrm{l} / \mathrm{s}^{53}$.

La idea de transferir agua del Júcar a la cuenca del Vinalopó perdura hasta hoy, si bien muy limitada y con trazado enteramente nuevo. Destaquemos, como dato invariable, la sistemática oposición de Valencia, que se ha intentado vencer con una progresiva rebaja de los objetivos del trasvase. El arquitecto Emilio Jover, en 1847, resumía la evolución así: «Los antiguos se proponían sangrar el río para traer aguas permanentes de riego y en este caso la obra sería de segura utilidad y probablemente menos costosa por aprovechar la rambla de Elche... En el día no se piden más que las aguas sobrantes en ciertas épocas y por consiguiente no es tan importante el beneficio y sería más costoso en razón a que es indispensable que las aguas vayan a parar a pantanos como el de Alicante, que es el mayor, de Almansa, Elda y algún otro que pueda construirse...» ${ }^{54}$. En la actualidad no se piensa sino en las aguas altamente contaminadas de la desembocadura, esperadas por las tierras alicantinas con fe y esperanza encomiables ${ }^{55}$.

Las mayores controversias actuales sobre posibles trasvases se centran en el Ebro, cuyos 84.958 kilómetros cuadrados de cuenca se reparten, si bien muy desigualmente, entre nueve comunidades autónomas, a cuya cabeza aparece muy destacada Aragón, con casi la mitad $(49,52 \%)$ de la superficie vertiente y más de la tercera parte $(38 \%)$ de la aportación anual, que, sin las múltiples sangrías, quedaría, a la altura de Flix $(96,96 \%$ de la cuenca), en torno a $19.500 \mathrm{Hm}^{3}$.

52 MORALES GIL, A. y VERA REBOLLO, J. F.: La Mancomunidad de los Canales del Taibilla. Murcia, Inst. Univ. de Geografía y Academia Alfonso X el Sabio, 1989, 133 pp.

53 GIL OLCINA, A.: «Aridez, riego localizado y agricultura de vanguardia en el litoral murciano de Águilas», en Paisajes del agua, Universidades de Valencia y Alicante, 1989, pp. 213-222.

54 «Noticia sobre el Canal del Júcar», 1847 (manuscrito), Canal del Júcar, Archivo M.O.P.U., Alicante.

55 BRU RONDA, C.: «El trasvase Júcar-Vinalopó», en Demanda y Economía del Agua en España, Alicante, 1988 , pp. 287-300.

56 BIELZA DE ORY, V. y MARÍN, J. M.: «Oferta-demanda hídrica en la cuenca del Ebro y posibles trasvases», en Demanda y Economía del Agua en España, Alicante, 1988, pp. 255-266. 
Esos datos físicos, conjugados con la trayectoria demográfica y evolución socioeconómica de la región, amén de amplias perspectivas de transformación en regadío y revitalización de una región desangrada por un éxodo masivo, explican que Aragón se oponga, con toda energía, a las peticiones de aguas sobrantes formuladas por Cataluña, País Vasco y Valencia, sin olvidar las esperanzas que, desde medio siglo atrás, abriga el sureste peninsular. Dichas solicitudes obedecen a demandas urbana, turística, agrícola e industrial, objeto, en algún caso, de valoraciones diferentes y matizadas ${ }^{57}$, o de negativas tajantes, fundamentadas en la supuesta inexistencia de excedentes, al considerar «agua sobrante a aquélla que no se utiliza porque no la desean quienes podrían hacerlo natural e inmediatamente; no podemos llamar agua sobrante a aquélla que deseándola utilizar los ribereños no pueden hacerlo por carecer de los medios precisos y porque éstos no son facilitados por los poderes públicos» ${ }^{58}$; muy recientemente el autor del razonamiento anterior, presidente de la Diputación General de Aragón, ha sugerido la potabilización de agua marina como medio de atender las necesidades de abastecimiento de Cataluña y subrayado el mandato constitucional de «armonizar el desarrollo territorial en España y, desde luego, concentrar los recursos más importantes en puntos muy concretos de la geografía española no garantiza el equilibrio territorial ${ }^{59}$.

Un planteamiento más moderado en la forma, aunque próximo en el fondo, es el que hace Bielza, para quien «la solución racional y justa es que aceptando el axioma de que el agua es del que la llueve, y una vez cubiertas todas las necesidades de las regiones excedentarias, se mantenga el principio de solidaridad y se trasvase el agua sobrante poniendo un precio al metro cúbico trasvasado» ${ }^{60}$.

Como se ha indicado, también el trasvase Tajo-Segura recibe críticas de muy variada índole. Además de objeciones técnicas y de rentabilidad, otras afectan a las relaciones entre las comunidades autónomas interesadas y a los mismos usos del agua, ya que las demandas urbana, turística e industrial compiten con ventaja y amenazan el destino agrícola. Aun cuando son seis las comunidades autónomas más o menos envueltas en el trasvase Tajo-Segura, los enfrentamientos se han producido primordialmente entre Murcia y Alicante, de un lado, y la Comunidad de Castilla-La Mancha o más concretamente la provincia de Toledo, por otro. Invocan unos política de Estado, con base en la mayor rentabilidad del agua y más aún en la seria amenaza de abandono de las tierras más productivas por la sobreexplotación y agotamiento de acuíferos; denuncian los otros depredación de un recurso vital y graves problemas de contaminación en el Tajo.

Esta «guerra del trasvase», la esbozada confrontación de intereses dispares en el Ebro o la difícil problemática del trasvase Júcar-Marina-Vinalopó mueven a reflexión sobre el futuro de las transferencias de recursos hídricos en el llamado «Estado de las Autonomías» e incluso de las cesiones de una superficie vertiente a otra en una misma comunidad autónoma.

La nueva Ley de Aguas de 2 de agosto de 1985, que ha sustituido a la benemérita y obsoleta de 1879 , concede máxima atención a la planificación hidrológica, que arranca de los planes de cuenca y culmina en el Plan Hidrológico Nacional, cuya meta es integrar aquéllos en un conjunto armónico, informado por principios de solidaridad, equilibrio y racionalidad.

57 BIELZA DE ORY y MARÍN: Op. cit., pp. 264-266.

58 GÓMEZ DE LAS ROCES, H.: «Los trasvases del Ebro». Seminario del Agua en Aragón. Zaragoza, Universidad de Zaragoza, 1984, p. 550, 1.

59 Diario «ABC» de Madrid, 20-IV-1990.

60 BIELZA DE ORY, V.: El estudio del medio ambiente desde el punto de vista geográfico (el bosque y el agua en España). Aspectos didácticos de Geografía. Zaragoza, I.C.E., 1985, p. 11. 
Piedra angular de la planificación constituyen las reestructuradas Confederaciones Hidrográficas, que, como organismos de cuenca, tienen a su cargo la elaboración de planes en dichos ámbitos y la difícil tarea de conciliar intereses, con frecuencia, muy encontrados. Cuestiones esenciales para los planes de cuenca son, como punto de partida, los inventarios de disponibilidades hídricas y necesidades actuales y futuras, a efectos del oportuno balance. Con esta información básica han de diseñarse las políticas de regulación y asignación de recursos a los distintos usos por orden de prioridad. Si el saldo es negativo, el plan debe examinar y proponer posibles alternativas para enjugar el déficit, planteando, en su caso, la transferencia de recursos foráneos. Necesariamente los referidos planes han de elaborarse desde una perspectiva de organización del espacio a través de la ordenación del territorio, con planificaciones acordes en los distintos medios y sectores.

Los planes de cuenca, una vez aprobados por el gobierno, sirven de base a la redacción del Plan Hidrológico Nacional, que, luego de informado por el Consejo Nacional del Agua, es remitido a las Cortes Generales para su aprobación; ésta implica el refrendo definitivo de aquéllos ${ }^{61}$. Cometidos primordiales del Plan Hidrológico Nacional son los de dirimir las alternativas que figuren en los planes de cuenca, resolver sobre transferencias hídricas, adscripción de caudales para actuaciones de planificación estatal y decisión de las obras de infraestructura hidráulica a ejecutar con cargo a los presupuestos generales del estado.

Tal y como se ve, no es sencilla la tarea que aguarda a las Confederaciones Hidrográficas, tenidas por algunos gobiernos autónomos como meras dependencias del Ministerio de Obras Públicas, ni fácil la redacción del Plan Hidrológico Nacional, marco legal para solventar duras confrontaciones autonómicas en torno a un recurso vital, escaso y cuyo consumo crece a ritmo vertiginoso.

61 PÉREZ PÉREZ, E.: Nueva Ley de Aguas y Cuenca del Segura. Murcia, Asociación de Economía y Sociología Agraria de la Región de Murcia, 1986, pp. 49-72. 